\title{
A newborn liver mass that never existed: a somber reminder of embryonic ties between umbilical vein and portal venous system
}

This article was published in the following Dove Press journal:

Hepatic Medicine: Evidence and Research

I3 December 201।

Number of times this article has been viewed

\section{Allah Haafiz' \\ Jonathan L Williams ${ }^{2}$ \\ Joel MAndres' \\ Don A Novak'}

'Pediatric Gastroenterology, Hepatology; ${ }^{2}$ Department of Pediatric Radiology, University of Florida College of Medicine, Gainesville, FL, USA
Correspondence: Allah B Haafiz UAMS College of Medicine, Pediatric Gastroenterology, Hepatology and Nutrition, Arkansas Children's Hospital, I Children's Way, Little Rock, AR 72202, USA

Tel +I 5013641004

Fax + $50 \mid 364629$

Email haafizallah@uams.edu

\begin{abstract}
A 6-day-old, known to have transposition of the great vessels, received care in the neonatal intensive care unit at a tertiary care center. A computed tomography scan was performed for abdominal distention and upper gastrointestinal bleeding, which revealed a "mass lesion" in the left liver lobe. Analysis of antecedent events and the clinical and laboratory course uncovered an iatrogenic etiology and pathogenesis of the lesion. As the nature of the lesion was clarified, no specific therapy was required. This case is presented to show a serious yet preventable complication of a commonly performed procedure.
\end{abstract}

Keywords: portal vein thrombosis, liver mass, umbilical venous catheter

Pediatric gastroenterology was consulted to evaluate abnormal liver tests and upper gastrointestinal (GI) bleeding in a 6-day-old Caucasian male, known to have transposition of the great vessels, requiring emergent atrial septostomy on the first day after birth. Before this procedure, at a referring hospital, the infant suffered a significant hypoxic event requiring dopamine, prostaglandin E1, sodium bicarbonate, and normal saline administered through umbilical veinous catheter. After the septostomy, his neonatal intensive care unit course was relatively stable except abdominal distention and recovery of small quantities of bright red blood recovered through nasogastric tube left on intermittent suctioning. The abdomen was soft but distended without hepatosplenomegaly. Initial laboratory investigations revealed albumin at $2.7 \mathrm{~g} / \mathrm{dL}$, total bilirubin $5.2 \mathrm{mg} / \mathrm{dL}$ (normal $<0.8 \mathrm{mg} / \mathrm{dL}$. The direct bilirubin was $0.9 \mathrm{mg} / \mathrm{dL}$, alanine transaminase of $842 \mathrm{U} / \mathrm{L}$ and the alanine transaminase of $195 \mathrm{U} / \mathrm{L}$ (normal $<45$ for both), alkaline phosphatase $146 \mathrm{U} / \mathrm{L}$, platelet count $115 \times 10^{9} / \mathrm{L}$ and an international normalized ratio of 5.9. Ultrasound of the liver revealed a heterogeneous $3.7 \times 2.9 \mathrm{~cm}$ "mass lesion" in the left hepatic lobe (Figure 1B) prompting further work up to rule out hepatoblastoma, hemangioendothelioma or mesenchymal hamartoma. Computed tomography scan of the abdomen revealed hyper-perfusion in the left lobe (Figure 1C) with areas of hypo- and hyper-attenuation (Figure 1D) suggesting compromised blood flow throughout the left lobe as the etiology of the lesion. Poor visualization of the left portal venous system and a clot in a branch of left portal vein with periportal edema (Figure 1D) supported the impression of thrombosis of left portal system. GI bleeding resolved when thrombocytopenia and coagulation parameters were optimized. All biochemical and hematological abnormalities resolved in 2 weeks. Three weeks latter, prior to reconstruction of the great vessels, a CT scan of the liver revealed resolution of the left liver lobe lesion except for minimal residual hypo-attenuation at the liver margin below the diaphragm. 

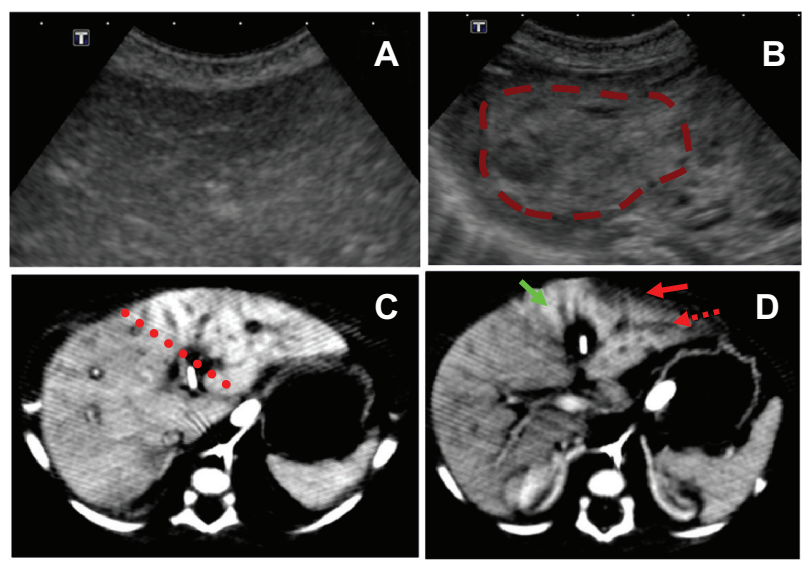

Figure I Left lobe lesion. (A) Normal ultrasound examination of the right lobe. (B) Ultrasound examination showing heterogeneous $3.7 \times 2.9 \mathrm{~cm}$ "mass lesion" in the left hepatic lobe (indicated by red interrupted line). (C) Computed tomography showing hyper-perfusion of left hepatic lobe (demarcated by red interrupted line). (D) Concurrent hyper-perfusion (green arrow), peripheral perfusion deficit (solid red arrow), and a clot in a branch of left portal vein (interrupted red arrow) indicate compromised vascular flow as the basis of the lesion.

This case illustrates the significance of correct positioning of umbilical venous catheters (UVC) to avoid compromised portal vascular flow. Although liver-related complications are uncommon, liver abscess, ${ }^{1}$ hepatic laceration. ${ }^{2}$ total parenteral nutrition ascites, and hepatic necrosis ${ }^{3}$ have been reported following hepatic placement of UVC. We attributed GI bleeding to tube-trauma in the setting of thrombocytopenia, because, without any additional therapies it resolved once the suction was discontinued. Similarly, although some degrees of portal hypertension is expected with thrombosis of portal venous system, the temporal profile (less than a week) is not supportive of portal hypertensive GI bleeding incidental to longstanding hepatic vascular or parenchymal diseases leading to portal hypertension. In the case of a neonate with abnormal liver tests, physicians should carefully review if a UVC was placed. If so, the correct placement of the catheter should be determined. The UVC initially noted to be at hepatic level was appropriately repositioned to lower cavo-atrial junction before atrial septostomy in this case. Hepatic abnormalities persisted for 2 weeks, however, presumably because of use during initial resuscitative efforts.

\section{Disclosure}

The authors report no conflicts of interest. This work was exempt from approval by the institutional review boards. Publication of this article was funded in part by the University of Florida Open-Access Publishing Fund.

\section{References}

1. Simeunovic E, Arnold M, Sidler D, Moore SW. Liver abscess in neonates. Pediatr Surg Int. 2009;25(2):153-156.

2. Yigiter M, Arda IS, Hicsonmez A. Hepatic laceration because of malpositioning of the umbilical vein catheter: case report and literature review. J Pediatr Surg. 2008;43(5):E39-E41.

3. Nakstad B, Naess PA, de LC, Schistad O. Complications of umbilical vein catheterization: neonatal total parenteral nutrition ascites after surgical repair of congenital diaphragmatic hernia. J Pediatr Surg. 2002;37(8):E21.

\section{Publish your work in this journal}

Hepatic Medicine: Evidence and Research is an international, peerreviewed, open access journal covering all aspects of adult and pediatric hepatology in the clinic and laboratory including the following topics: Pathology, pathophysiology of hepatic disease; Investigation and treatment of hepatic disease; Pharmacology of drugs used for

\section{Dovepress}

the treatment of hepatic disease. Issues of patient safety and quality of care will also be considered. The manuscript management system is completely online and includes a very quick and fair peer-review system, which is all easy to use. Visit http://www.dovepress.com/ testimonials.php to read real quotes from published authors. 